\title{
Abortive phage infection and restriction/modification activities directed by pTR2030 determinants are enhanced by recombination with conjugal elements in lactococci
}

\author{
DenNis A. Romero ${ }^{1}$ and Todd R. Klaenhammer*1,2 \\ Departments of Microbiology ${ }^{1}$ and Food Science ${ }^{2}$, Southeast Dairy Foods Research Center, \\ North Carolina State University, Raleigh, NC 27695, USA
}

(Received 17 October 1989; revised 16 February 1990; accepted 8 June 1990)

\begin{abstract}
The recombinant plasmid pTK6 is composed of a $13.6 \mathrm{~kb}$ fragment from pTR2030 encoding phage resistance determinants for restriction/modification $\left(\mathrm{R}^{+} / \mathbf{M}^{+}\right)$and abortive phage infection $\left(\mathrm{Hsp}^{+}\right)$cloned into shuttle vector pSA3 (erythromycin resistance, $\mathrm{Em}^{\mathrm{r}}$ ). Conjugal matings were performed to mobilize pTK6-encoded markers from Lactococcus lactis subsp. lactis MMS362 and MG1363. $\mathrm{Em}^{\mathrm{r}}$ transconjugants were recovered at $10^{-6}$ per input donor and harboured pTK6 or recombinant plasmids not found in either parental strain. The recombinant plasmids (pTRK78 and pTRK79) encoded $\mathrm{Em}^{r}, \mathrm{Hsp}^{+}$and $\mathrm{R}^{+} / \mathrm{M}^{+}$, and transferred at high frequency in second-round matings. Mobilization of pTK6 from the otherwise plasmid-free donor, $L$. lactis MG1363, confirmed the presence of a conjugal element in this strain. Phage resistance in transconjugants containing pTRK78 and pTRK79 was markedly enhanced over pTK6-directed $\mathrm{Hsp}^{+}$and $\mathrm{R}^{+} / \mathrm{M}^{+}$. In $L$. lactis LM2345 transconjugants, a reduction in plaque size was accompanied by a significant decrease in the efficiency of plaquing for phages $\mathrm{c} 2\left(10^{-2}\right.$ to $\left.10^{-6}\right)$ and p2 $\left(<10^{-9}\right)$. L. lactis NCK203 transconjugants containing pTRK78 or pTRK79 exhibited an additional 100-1000fold reduction in the plaquing efficiency of $\phi 48\left(10^{-4}\right.$ to $\left.10^{-5}\right)$ over pTK6 imposed restriction $\left(10^{-2}\right)$. Increased resistance to phage was a consequence of the physical interaction of pTR2030-derived sequences on pTK6 with a conjugal element resident in the donor strains.
\end{abstract}

\section{Introduction}

Bacteriophages have long presented a problem in the manufacture of fermented dairy products. A number of plasmid-associated phage resistance mechanisms have recently been reported within Lactococcus. These include inhibition of phage adsorption, restriction/modification activities, and a mechanism which causes abortive phage infection (Klaenhammer, 1987; Sanders, 1988). After mobilization of lactose-fermenting ability from a phageinsensitive starter strain, Lactococcus lactis subsp. lactis ME2, Klaenhammer \& Sanozky (1985) isolated a selftransmissible plasmid, pTR2030, that conferred resistance to bacteriophage attack. The efficacy of pTR2030directed phage resistance was demonstrated by its conjugal transfer to a variety of lactococci, where it inhibited phage proliferation (Jarvis \& Klaenhammer, 1986; Sanders et al., 1986; Sing \& Klaenhammer, 1986;

Abbreviations: e.o.c., efficiency of infective centre formation; e.o.p., efficiency of plaquing; Hsp, heat-sensitive phage resistance; m.o.i., multiplicity of infection; $\mathrm{R} / \mathrm{M}$, restriction/modification.
Steenson \& Klaenhammer, 1985). More significantly, strategies were developed to introduce pTR2030 by conjugation into industrial starter culture strains without affecting desired fermentation characteristics (Sing \& Klaenhammer, 1986; Sanders et al., 1986). These pTR2030-containing transconjugants have been successfully used in commercial starter systems, where they exhibit improved resistance to bacteriophage attack (Klaenhammer, 1987; Sanders, 1988).

pTR2030 is a $46.2 \mathrm{~kb}$ plasmid that encodes both abortive phage infection (Hsp) and restriction/modification (R/M) activity (Hill et al., 1989a). The Hsp ${ }^{+}$ phenotype is defined as a reduction in plaque size accompanied by a less than 10-fold decrease in the efficiency of plaquing (e.o.p.) (Klaenhammer \& Sanozky, 1985), and can be further characterized by its action on different phage species (Jarvis \& Klaenhammer, 1986). In standard plaque assays, reduced plaque size at a lowered e.o.p. is the phenotype seen with prolate-headed phage c2. In contrast, small isometricheaded phages fail to form visible plaques on $\mathrm{PTR} 2030$ containing strains. $\mathrm{R}^{+} / \mathbf{M}^{+}$is defined within the $L$. lactis 


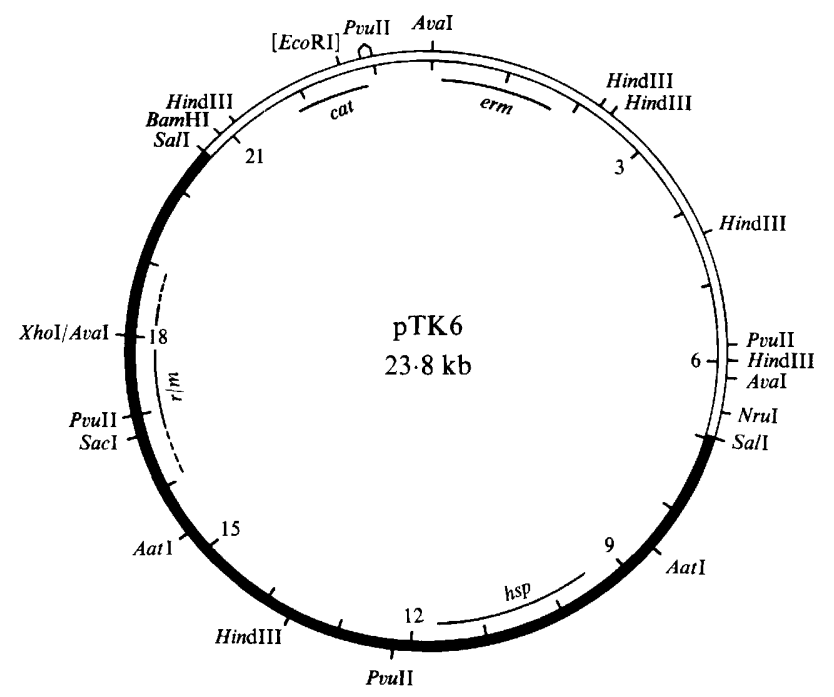

Fig. 1. Circular restriction map of pTK6. The bold line denotes the $13.6 \mathrm{~kb}$ fragment from pTR2030; the open line denotes the pSA3 part of the plasmid. See text for explanation of abbreviations.

NCK203 background, where phage $\phi$ nck202.48 ( $\phi 48)$, which is capable of circumventing Hsp, is restricted at a level of $10^{-3}$ (Hill et al., 1989a). The locations of the hsp and $r / m$ genetic determinants were identified on pTR2030 and subcloned onto the shuttle vector pSA3 (Hill et al., 1989a,b). The resulting plasmid, designated pTK6, is $23.8 \mathrm{~kb}$ in size and contains a $13.6 \mathrm{~kb}$ fragment from pTR2030 encoding $\mathrm{Hsp}^{+}$and $\mathrm{R}^{+} / \mathrm{M}^{+}$(Fig. 1). Phage resistance conferred by pTK6 was less than pTR2030 in that the plaque size for phage $\mathrm{c} 2$ was not reduced to the same extent, plaque formation by small isometric-headed phages was not completely inhibited, and restriction of $\phi 48$ was reduced 10 -fold. The deletion in pTR2030 identifying the $h s p r / m$ region had no effect on conjugal transfer functions (Hill et al., 1989b), indicating that pTK 6 is unlikely to be self-transmissible. The utility of conjugal strategies for the transfer of plasmid-encoded phage resistance within lactococci prompted us to examine the ability of indigenous conjugal elements to mobilize pTK6. This study describes the mobilization of pTK6 via a recombination process and the subsequent isolation of pTK6-derived cointegrate plasmids that exhibit phage resistance enhanced over the pTK6 and pTR2030 phenotypes. The results also suggested the presence of a transposable element residing within the cloned pTR2030 fragment and a potential role for recombination in the dissemination of phage resistance within the lactococci.

\section{Methods}

Bacterial strains, plasmids and phages. The L. lactis strains, plasmids and phages used in this study are listed in Table 1. L. lactis cultures were propagated at $30^{\circ} \mathrm{C}$ in $\mathrm{M} 17$ broth (Terzaghi \& Sandine, 1975) supplemented with $0.5 \%(\mathrm{w} / \mathrm{v})$ glucose (M17G) or lactose (M17L). Unless otherwise noted, antibiotics were added to the following concentrations (in $\mu \mathrm{g} \mathrm{ml}^{-1}$ ): chloramphenicol $(\mathrm{Cm}), 5$; erythromycin (Em), 10; rifampicin (Rif), 50; spectinomycin (Spc), 300; streptomycin (Str), 1000. Escherichia coli strains were propagated in LB broth (Silhavy et al., 1984). E. coli HB101 containing pSA3 or pTK6 (Hill et $a l ., 1989 b)$ was propagated in media containing $\mathrm{Cm}\left(20 \mu \mathrm{g} \mathrm{ml}^{-1}\right)$ or tetracycline $\left(\mathrm{Tc} ; 10 \mu \mathrm{g} \mathrm{ml}^{-1}\right.$ ) and served as a source of DNA for transformation experiments.

Phage propagation and plaque assays. Standard plaque assays and preparation of phage lysates were as described by Terzaghi \& Sandine (1975). All assays were performed at $30^{\circ} \mathrm{C}$. The number of infective centres was determined using an adaptation of the method described by Keogh (1973). Briefly, strains were propagated to an optical density $\left(\mathrm{OD}_{600}\right)$ of $0.7-0.9$ at $30^{\circ} \mathrm{C}$. Phages were adsorbed to cells in $5 \mathrm{ml}$ culture at a multiplicity of infection (m.o.i.) of 0.1 or less, in the presence of $50 \mathrm{mM}-\mathrm{CaCl}_{2}$, and incubated for $15-20 \mathrm{~min}$ at room temperature. Cells were recovered by centrifugation at $4000 \mathrm{~g}$ for $10 \mathrm{~min}$, washed twice in $25 \mathrm{ml} \mathrm{10 \% (v/v)} \mathrm{M17G} \mathrm{containing} 50 \mathrm{~mm}$ $\mathrm{CaCl}_{2}$, and resuspended in $5 \mathrm{ml}$ of the same solution. Appropriate dilutions were combined with a sensitive indicator strain and plated as in standard plaque assays. The efficiency of infective centre formation (e.o.c.) was calculated as the number of infective centres on the test strain divided by the number of infective centres on the sensitive indicator. The results of standard plaque assays and infective centre determinations were averaged from at least two independent trials.

$\mathrm{R} / \mathrm{M}$ activity was detected using the phage-host pair $\phi 48 / \mathrm{NCK} 203$ since pTK6 and pTR2030 do not confer the ability to restrict phages $\mathrm{c} 2$ and 22 in the LM2301/LM2345 background (Hill et al., 1989a). Derivatives of $L$. lactis NCK203 containing pTK6 or pTR2030 restrict the small isometric-headed phage $\phi 48$ at levels of $10^{-2}$ to $10^{-3}$, respectively. Phage $\phi 48$ escapes Hsp interference; therefore, plaque size is not affected.

Plasmid isolation and characterization. Plasmid DNA was isolated as described by Anderson \& McKay (1983). Plasmids from E. coli V517 and $\mathrm{J} 53$ were used as reference mobility standards. pSA3 and pTK6 DNA, used in transformation experiments, was isolated from $E$. coli as described by Rodriguez \& Tait (1983).

Nucleic acid was transferred from agarose gels onto MSI Magnagraph nylon membranes (Micron Separations, Westboro, Massachusetts, USA) as described by Southern (1975). [32 P]dCTP-labelled probes were prepared using a Multiprime DNA Labelling Kit (Amersham). Radiolabelled probes were separated from unincorporated nucleotides using Sephadex G50 spin columns (Boehringer Mannheim Biochemicals). Hybridization reactions were performed using an Omni-blot apparatus (American Bionetics, Emeryville, California, USA) as described by Luchansky et al. (1989).

Conjugation. Solid-surface conjugal matings on M17 agar were performed as described by McKay et al. (1980). Frequencies of conjugal transfer were calculated as the number of transconjugants recovered per input donor cell. L. lactis MMS362 is recombinationdeficient $\left(\mathrm{Rec}^{-}\right)$and contains the $48.2 \mathrm{~kb}$ self-transmissible plasmid pRS01 (Anderson \& McKay, 1984b).

Transformation. L. lactis protoplast transformation was performed as described by von Wright $e$ t al. (1985). Antibiotic-resistant transformants were selected on $\mathrm{M} 17$ regeneration agar supplemented with Em $\left(5 \mu \mathrm{g} \mathrm{ml}^{-1}\right)$. 
Table 1. Bacterial strains, plasmids and phages

\begin{tabular}{|c|c|c|}
\hline $\begin{array}{l}\text { Strain, plasmid } \\
\text { or phage }\end{array}$ & Relevant characteristics* & Description (reference) \\
\hline \multicolumn{3}{|l|}{ L. lactis } \\
\hline LM2301 & str-l, plasmid-free & $\begin{array}{l}\text { Conjugation host (Snook \& McKay, 1981) derived from NCDO } 2031 \text { (Davies et al., } \\
\text { 1981) }\end{array}$ \\
\hline LM2345 & $s p c-4$ rif-5, plasmid-free & Conjugation host (Anderson \& McKay, 1984b) \\
\hline MG1363 & Plasmid-free & Conjugation host (Gasson, 1983) derived from NCDO 712 (Davies et al., 1981) \\
\hline MMS362 & str-14 $\mathrm{Rec}^{-} \mathrm{pRS} 01$ & $\mathrm{Rec}^{-}$conjugation host (Anderson \& McKay, 1984b) \\
\hline T-WS1 & $\mathrm{Hsp}^{+} \mathrm{pTR} 2030$ & LM0230/pTR2030 (Sing \& Klaenhammer, 1986) \\
\hline NCK 203 & str-15 & Conjugation host (Hill et al., 1989a) \\
\hline NCK6 & pTK6 & MG1363/pTK6 (Hill et al., 1989b) \\
\hline NCK161 & str-1, pTK6 & LM2301/pTK6 \\
\hline NCK166 & str-14, Rec ${ }^{-}$pRS01, pSA3 & MMS362/pSA3 \\
\hline NCK 167 & str-14, Rec ${ }^{-}$pRS01, pTK6 & MMS362/pTK6 \\
\hline NCK 178 & $s p c-4$ rif-5, pTRK 78 & LM2345/pTRK 78; transconjugant from NCK $167 \times$ LM2345 mating \\
\hline NCK 179 & $s p c-4$ rif-5, pTRK 79 & LM2345/pTRK 79; transconjugant from NCK6 $\times$ LM2345 mating \\
\hline NCK222 & str-15, pTRK78 & NCK203/pTRK 78; transconjugant from NCK178 $\times$ NCK203 mating \\
\hline NCK223 & str-15, pTRK 79 & NCK203/pTRK 79; transconjugant from NCK179 $\times$ NCK203 mating \\
\hline \multicolumn{3}{|r|}{ 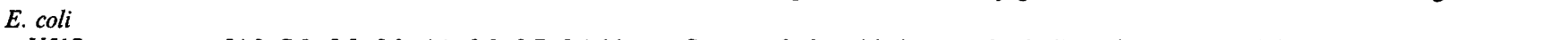 } \\
\hline V517 & $54 \cdot 2,7 \cdot 3,5 \cdot 5,5 \cdot 2,4 \cdot 1,3 \cdot 0,2 \cdot 7,2 \cdot 1 \mathrm{~kb}$ & Source of plasmid size standards (Macrina et al., 1978) \\
\hline J53 & $34.5 \mathrm{~kb}$ & Source of plasmid size standard (Klaenhammer et al., 1978) \\
\hline \multicolumn{3}{|l|}{ Plasmids } \\
\hline pSA3 & $\mathrm{Em}^{\mathrm{r}} \mathrm{Cm}^{\mathrm{r}} \mathrm{Tc} \mathrm{c}^{\mathrm{r}}, 10 \cdot 2 \mathrm{~kb}$ & Shuttle vector (Dao \& Ferretti, 1985) \\
\hline pTK6 & $\mathrm{Em}^{\mathrm{r}} \mathrm{Hsp}^{+} \mathbf{R}^{+} / \mathbf{M}^{+} \mathrm{Cm}^{\mathrm{r}}, 23.8 \mathrm{~kb}$ & pSA3 containing $13.6 \mathrm{~kb}$ pTR2030 fragment (Hill et al., 1989b) \\
\hline pTRK28 & $\mathrm{Em}^{\mathrm{r}} \mathrm{Cm}^{\mathrm{r}} \mathrm{Tc} \mathrm{c}^{\mathrm{r}}, 11.0 \mathrm{~kb}$ & pSA3 : :iso-ISSI (Romero \& Klaenhammer, 1990) \\
\hline pRS01 & $\mathrm{Tra}^{+} \mathrm{Clu}^{ \pm}, 48 \cdot 2 \mathrm{~kb}$ & Resident plasmid of MMS362 (Anderson \& McKay, 1984) \\
\hline pTRK78 & $\mathrm{Em}^{r} \mathrm{Hsp}^{+} \mathrm{R}^{+} / \mathbf{M}^{+} \mathrm{Clu}^{+} \mathrm{Tra}^{+}$ & pTK6::pRS01 from NCK178 \\
\hline pTRK79 & $\mathrm{Em}^{\mathrm{r}} \mathrm{Hsp}^{+} \mathbf{R}^{+} / \mathbf{M}^{+} \mathrm{Clu}^{+} \mathrm{Tra}^{+}$ & pTK6: : conjugal element MG1363 (from NCK179) \\
\hline pTR2030 & $\mathrm{Hsp}^{+} \mathrm{R}^{+} / \mathrm{M}^{+} \mathrm{Tra}^{+}, 46 \cdot 2 \mathrm{~kb}$ & (Klaenhammer \& Sanozky, 1985) \\
\hline \multicolumn{3}{|l|}{ Phages } \\
\hline $\mathrm{c} 2$ & Prolate & Homologous for $L$. lactis LM2301/LM2345/MG1363/MMS362/T-WS1 \\
\hline $\mathrm{p} 2$ & Small isometric & Homologous for $L$. lactis LM2301/LM2345/MG1363/MMS362/T-WS1 \\
\hline$\phi$ nck202.48 & Small isometric & Homologous for $L$. lactis $\mathrm{NC} 203$ \\
\hline
\end{tabular}

*Abbreviations: Cm, chloramphenicol; Em, erythromycin; Rif, rifampicin; Spc, spectinomycin; Str, streptomycin; Tc, tetracycline; Hsp, abortive phage infection; R/M, restriction/modification; Tra, conjugal proficiency; Rec, host recombination; Clu, cell clumping ability (aggregation); $r$, resistant; $(+)$, positive; $(-)$, negative.

\section{Results}

\section{Conjugal mobilization of pTK6}

To determine if pTK6 was self-transmissible, L. lactis NCK161 [LM2301 (pTK6)] and NCK6 [MG1363 (pTK6)], were used as conjugal donors of $\mathrm{Em}^{\mathrm{r}}$ in matings with $L$. lactis $\mathrm{LM} 2345$. $\mathrm{Em}^{\mathrm{r}}$ was not transferred from NCK161, indicating that pTK6 was not self-transmissible. $\mathrm{Em}^{\mathrm{r}}$ transconjugants were recovered from NCK $6 \times$ LM2345 matings at a frequency of $5 \times 10^{-6}$. Transconjugants contained either pTK 6 or a large plasmid (Fig. 2, lane F) not found in either of the parental strains. The latter transconjugants all displayed a clumping phenotype in broth and transferred $\mathrm{Em}^{\mathrm{r}}$ at high efficiency (about 1) in second-round matings. This suggested a physical linkage between pTK6 and a conjugal element residing within MG1363. A representative transconjugant, designated NCK179, was selected for further study.
To examine pTK6 mobilization further, pSA3 and pTK6 were transformed into the $\mathrm{Rec}^{-}$strain $L$. lactis MMS362, which contains the self-transmissible plasmid pRS01 (Anderson \& McKay, 1984b). The transformants were used as conjugal donors of $\mathrm{Em}^{\mathrm{r}}$ in matings with $L$. lactis LM2345. Transfer of $\mathrm{Em}^{\mathrm{r}}$ from NCK167 [MMS362 (pTK6)] occurred at frequencies of $2 \times 10^{-5}$, whereas no $\mathrm{Em}^{\mathrm{r}}$ transconjugants were recovered from NCK166 [MMS362 (pSA3)] donors. The inability of pRS01 to mobilize pSA3 indicated that the cloned $13.6 \mathrm{~kb}$ fragment was necessary for conjugal transfer of pTK6. $\mathrm{Em}^{\mathrm{r}}$ transconjugants contained either pTK6 or a large plasmid suspected to be a pTK6::pRS01 cointegrate (Fig. 2, lane D). The latter exhibited either a clumping $\left(\mathrm{Clu}^{+}\right)$or non-clumping $\left(\mathrm{Clu}^{-}\right)$phenotype. In secondround matings, transconjugants containing the putative cointegrate transferred $\mathrm{Em}^{r}$ at frequencies of about 1 $\left(\mathrm{Clu}^{+}\right)$and $10^{-5}\left(\mathrm{Clu}^{-}\right)$. These results corresponded to transfer frequencies associated with the clumping phenotype encoded by pRS01 (Anderson \& McKay, 1984b) 


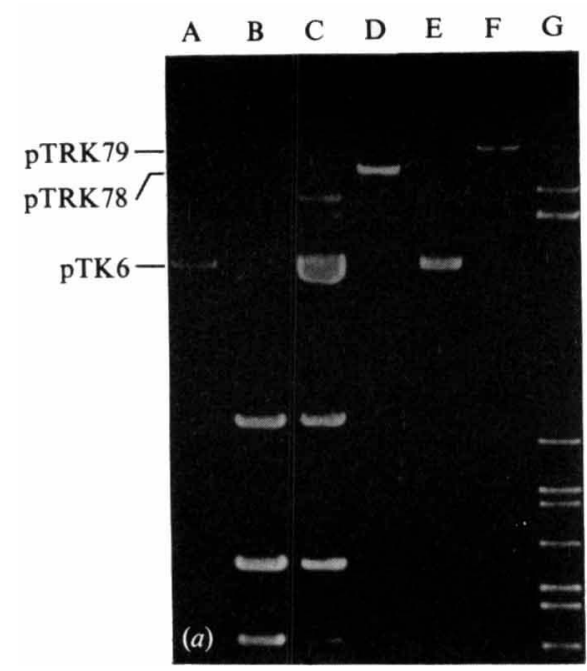

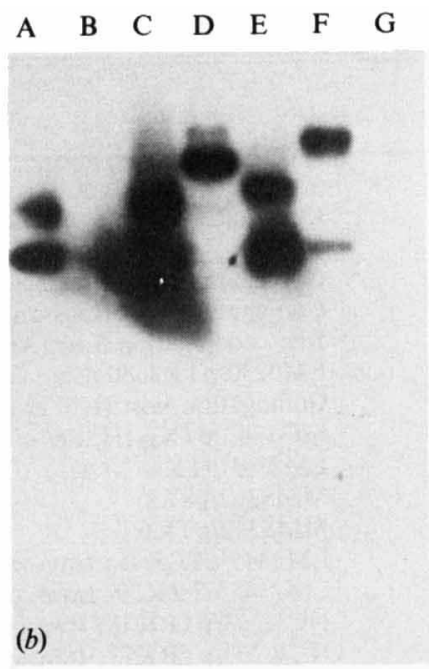

Fig. 2. Plasmid profiles (a), and corresponding autoradiogram $(b)$ probed with ${ }^{32} \mathrm{P}$-labelled pSA3, of L. lactis strains used in pTK6 mobilization experiments. Lane A, pTK6 (from E. coli HB101); lane B, MMS362; lane C, MMS362/pTK6; lane D, NCK178; lane E, MG1363/pTK6; lane F, NCK179; lane $\mathrm{G}, E$. coli $\mathrm{V} 517(54 \cdot 2,7 \cdot 3,5 \cdot 5,5 \cdot 2,4 \cdot 1,3 \cdot 0,2 \cdot 7$ and $2.1 \mathrm{~kb})$ and $\mathrm{J} 53(34.5 \mathrm{~kb})$ plasmid standards. Additional bands seen in lanes A, C, and E represent open circular or linear forms of pTK6 generated upon isolation.

Table 2. Effects of pTR2030, pTK6 and pTK6-cointegrates ( $p$ TRK78 and pTRK79) on the e.o.p. and plaque size of phages $c 2$ (protate) and $p 2$ (small isometric) attacking L. lactis

\begin{tabular}{llccccc}
\hline \hline & & \multicolumn{2}{c}{ Phage c2* } & & \multicolumn{2}{c}{ Phage p2* } \\
\cline { 3 - 4 } \cline { 6 - 7 } Strain & Plasmid & E.o.p. & $\begin{array}{c}\text { Plaque } \\
\text { size }(\mathrm{mm})\end{array}$ & & E.o.p. & $\begin{array}{c}\text { Plaque } \\
\text { size (mm) }\end{array}$ \\
\hline LM2345 & None & $1 \cdot 0$ & $2 \cdot 0-2 \cdot 5$ & & 1.0 & 1.0 \\
NCK178 & pTRK78 & $10^{-2}$ & $<0.2 \dagger$ & & $<10^{-9}$ & - \\
NCK179 & pTRK79 & $10^{-6}$ & $<0 \cdot 2 \dagger$ & & $<10^{-9}$ & - \\
T-WS1 & pTR2030 & 0.57 & $0.5-1 \cdot 0$ & & $<10^{-9}$ & - \\
NCK161 & pTK6 & 0.33 & $0.5-1 \cdot 0$ & & 0.82 & 0.5 \\
\hline \hline
\end{tabular}

* Starting phage titre approximately $10^{9}$ p.f.u. $\mathrm{ml}^{-1}$.

$\dagger$ Mutant phage producing plaques of $1.0 \mathrm{~mm}$ diameter appeared at frequencies of $10^{-4}$ (NCK 178) and $10^{-6}$ (NCK 179).

and indicated a physical linkage between pTK6 and pRS01. A representative $\mathrm{Clu}^{+}$transconjugant, designated NCK 178, containing a putative pTK6::pRS01 cointegrate, was selected for further study.

\section{Phage resistance phenotype of transconjugants NCK178 and NCK179}

The phage resistance phenotypes of NCK178 and NCK 179 were compared to those of isogenic strains containing pTK6, pTR2030, or no plasmid (sensitive indicator). Results of standard plaque assays using phages c2 (prolate-headed) and p2 (small isometricheaded) are shown in Table 2. Phage resistance in NCK 178 and NCK179 was markedly greater than that of strains containing pTK 6 or pTR2030. Inhibition of phage c2 was seen as a reduction in e.o.p. to $10^{-2}$ (NCK178) and $10^{-6}$ (NCK179) accompanied by a reduction in plaque size to less than $0.2 \mathrm{~mm}$. At frequencies of $10^{-4}$ (NCK178) and $10^{-6}$ (NCK179), plaques of $1 \mathrm{~mm}$ diameter began to appear. Plaque assays with phage purified from these large plaques indicated that they were mutant $\mathrm{c} 2$ phage capable of circumventing the inhibition imposed by pTRK 78, pTRK79 and pTR2030. For phage p2, NCK178 (pTRK 78) and NCK179 (pTRK 79) completely inhibited plaque formation. This is in contrast to NCK 161 (pTK6), where only a slight reduction in e.o.p. and a reduced plaque size for phage p2 were observed. Therefore, the level of phage resistance in NCK 178 and NCK 179 had returned to levels equal to or greater than that imposed by pTR2030 in T-WS1.

\section{Linkage of $E m^{r}$ and phage resistance to pTRK78 and pTRK79}

The plasmid profiles of NCK 178, NCK179 and parental strains are shown in Fig. 2(a). The pTK6-recombinant plasmids, pTRK 78 and pTRK 79, are shown in lanes D and F. In rapid plasmid preparations of NCK178 and 
Table 3. Effects of pTR2030, pTK6 and pTK6-cointegrates ( $p$ TRK78 and $p T R K 79$ ) on the e.o.p. and e.o.c. of phages $c 2$ (prolate) and p2 (small isometric)

\begin{tabular}{llccccc}
\hline \hline & & \multicolumn{2}{c}{ Phage c2* } & & \multicolumn{2}{c}{ Phage p2* } \\
Strain & Plasmid & E.o.p. & E.o.c. & & E.o.p. & E.o.c. \\
\hline LM2345 & None & $1 \cdot 0$ & $1 \cdot 0$ & & $1 \cdot 0$ & 1.0 \\
NCK178 & pTRK78 & $10^{-2}$ & 0.05 & & $<10^{-7}$ & 0.09 \\
NCK179 & pTRK79 & $<10^{-6}$ & $0 \cdot 01$ & & $<10^{-7}$ & 0.08 \\
T-WS1 & pTR2030 & $0 \cdot 28$ & $0 \cdot 21$ & & $<10^{-7}$ & 0.07 \\
NCK161 & pTK6 & 0.50 & 0.40 & & 0.49 & 0.22 \\
\hline \hline
\end{tabular}

NCK179, only a single plasmid band was visible, suggesting the cointegrate to be the predominant plasmid form. Plasmid DNA was transferred to a nylon membrane and probed with ${ }^{32}$ P-labelled pSA3 (Fig. $2 b$ ). Specific hybridization to pTK6 (both covalently closed circular and linear forms) was seen in the control (lane A) and donors NCK 167 (lane C) and NCK6 (lane E). The predominant signal in transconjugants NCK178 and NCK 179 corresponded to the respective presumptive cointegrates indicated in Fig. 2(a) confirming the presence of pSA3 sequences in these plasmids. A hybridizing band, comigrating with pTK6, was also visible in NCK179 (Fig. 2b, lane F), suggesting the presence of free pTK6. No hybridization was observed to the plasmid complement of MMS362 (lane B) or to chromosomal DNA isolated from MG1363 (data not shown).

To establish plasmid linkage of $\mathrm{Em}^{\mathrm{r}} \mathrm{Hsp}^{+} \mathrm{Clu}^{+}$to pTRK78 and pTRK79, NCK178 and NCK179 were subjected to consecutive propagation at $37^{\circ} \mathrm{C}$ in the absence of selective $(\mathrm{Em})$ pressure. After ten consecutive passages (about 60 generations), 1 of 50 colonies $(2 \%)$ examined from NCK 178 and 1 of 50 colonies examined from NCK 179 were $\mathrm{Em}^{\mathrm{s}}$. The $\mathrm{Em}^{\mathrm{s}}$ derivatives were also $\mathrm{Hsp}^{-}$and $\mathrm{Clu}^{-}$. pTRK 78 and pTRK 79 were not detected in rapid plasmid DNA preparations of either of the $\mathrm{Em}^{\mathrm{s}}$ $\mathrm{Hsp}^{-} \mathrm{Clu}^{-}$isolates, consistent with plasmid linkage of these phenotypes.

\section{Phage resistance encoded by pTRK78 and pTRK79 is Hsp}

The formation of infective centres was examined to ascertain the possible mechanism of phage resistance conferred by pTRK78 and pTRK79. Table 3 shows a comparison between the efficiency of plaquing and the efficiency at which infective centres were formed in strains containing pTR2030 or pTK6-derived plasmids.
For phage c2, NCK178 gave an e.o.c. value of 0.05 , which corresponds to an e.o.p. of $10^{-2}$. For NCK179, an e.o.c. of 0.01 indicated that release of viable $c 2$ phage was reduced by $99 \%$ to $10^{-2}$. In contrast, no visible plaques were observed in the standard plaque assays run in parallel (e.o.p. $<10^{-6}$ ). This suggested that, although $1 \%$ of the infected NCK179 cells produced viable c2 progeny, an insufficient number of phage were released to cause visible plaque formation in standard plaque assays. The e.o.c. levels for NCK 178 and NCK179 with phage $c 2$ were reduced approximately 10 -fold compared with T-WS1 (pTR2030) and NCK161.

With phage p2, NCK178 and NCK179 gave e.o.c. values of 0.09 and 0.08 , respectively. Despite the complete inhibition of plaque formation in standard plaque assays, less than a 100 -fold decrease in e.o.c. was observed. As described above for phage $\mathrm{c} 2$, it is probable that an insufficient number of $\mathrm{p} 2$ phage progeny were released by successfully infected cells to produce a visible plaque in standard plaque assays. The e.o.c. levels for NCK 178 and NCK 179 were comparable to T-WS1 and about $40 \%$ lower than NCK 161 .

These data indicated that for phages $c 2$ and $\mathrm{p} 2$, pTRK 78 and pTRK 79 resulted in a 91-99\% reduction in the number of successful phage infections which released viable phage. These levels are typical of pTK6- and pTR2030-encoded Hsp reactions on phages c2 and p2.

Restriction/modification activity of pTRK78 and pTRK79

To determine if the cointegrate plasmids possessed $R / M$ activities, pTRK78- and pTRK79-encoded $\mathrm{Em}^{\mathrm{r}}$ were conjugally transferred into $L$. lactis NCK203. In this host background, $\mathbf{R} / \mathbf{M}$ activity can be evaluated independently of Hsp using phage $\phi 48$ (Hill et al., 1989a). Em ${ }^{r}$ transconjugants were recovered and a representative isolate from each mating was tested for phage resistance. The transconjugants, NCK222 (pTRK 78) and NCK223 
(PTRK179), restricted $\phi 48$ at e.o.p. values of $10^{-4}$ and $10^{-5}$, respectively. These levels of restriction are $10-1000$ times higher than those elicited by pTK6 $\left(10^{-2}\right)$ and pTR2030 $\left(10^{-3}\right)$. To confirm R/M activity, a cycle of host-dependent phage replication was performed. After growth through NCK222 (pTRK78) or NCK223 (pTRK 79), phage from single plaque isolates were no longer restricted by hosts containing pTK6, pTRK 78 or pTRK 79, indicating that a similar $R / M$ system was encoded by all three plasmids. Following propagation through NCK203, thereby removing any pTK6-, pTRK 78- or pTRK79-encoded modification, $\phi 48$ was again restricted by hosts containing these plasmids, to the original degrees.

\section{Phage resistance is encoded by pTK6}

NCK167 and NCK6 did not exhibit resistance to phages c2 and p2 beyond that seen with NCK161 (data not shown). However, it remained possible that a resistance mechanism other than pTK6-encoded Hsp or R/M was recovered or activated in the conjugation process which formed pTRK78 and pTRK79. To determine if a resistance mechanism residing on the conjugal elements was activated during mobilization, MMS362 and MG1363 were transformed with pTRK28 (pSA3 : : isoISS1; Romero \& Klaenhammer, 1990). The transformants were then used as conjugal donors of $\mathrm{Em}^{\mathrm{r}}$ in matings with LM2345 to generate cointegrates with the conjugal element residing in MMS362 and MG1363. $\mathrm{Em}^{\mathrm{r}}$ transconjugants were obtained at frequencies comparable to pTK6. Randomly selected isolates containing pTRK 28 and pTRK28-derived cointegrates remained fully sensitive to phages $\mathrm{c} 2$ and $\mathrm{p} 2$ (data not shown). Therefore, a resistance mechanism linked to the conjugal elements was not identified during the mobilization process.

\section{Discussion}

In the course of establishing plasmid linkage for $\mathrm{Hsp}^{+}$ with cointegrates pTRK 78 and pTRK 79, we discovered that the transconjugants L. lactis NCK178 and NCK179 harbouring these plasmids exhibited an enhanced phage resistance phenotype when compared to the parental donors containing pTK6. NCK178 and NCK179 possessed the most pronounced phage inhibition among the transconjugants tested. Several lines of experimental evidence indicated that the recombinant plasmids were formed via cointegration between pTK6 and resident conjugal elements in the donor strains, and selected following conjugation. pTK6 was not self-transmissible. Conjugal mobilization from $L$. lactis MMS362 and
MG1363 resulted in transconjugants that harboured large recombinant plasmids, represented by pTRK 78 and pTRK79, not found in either parental strain. pTRK78 and pTRK79 conferred $\mathrm{Hsp}^{+}$and $\mathrm{R}^{+} / \mathrm{M}^{+}$ typical of pTK6 or pTR2030, albeit at increased levels. Through second-round conjugal matings, standard plaque and e.o.c. assays, plasmid curing and hybridization experiments, the recombinant plasmids were shown to encode traits $\left(\mathrm{Em}^{\mathrm{r}} \mathrm{Hsp}^{+} \mathrm{R}^{+} / \mathrm{M}^{+} \mathrm{Clu}^{+} \mathrm{Tra}^{+}\right)$associated with both pTK 6 and the conjugal elements.

The ability of pTK 6 to be mobilized from the plasmidfree strain $L$. lactis MG1363 is consistent with the suspected presence of a conjugal element in this strain. Similar observations have been made with the transfer of a deleted lactose plasmid, pMG820, and various in vitro constructed derivatives from MG1363 (van der Lelie, 1989). The progenitor for MG1363, L. lactis 712 , has been reported to contain a conjugal element responsible for the mobilization of plasmid-borne lactose metabolic genes (Gasson, 1983; Fitzgerald \& Gasson, 1988). The conjugal element is conjectured to be an episome, which may account for its low copy number and inability to be visualized in plasmid preparations. Isolation of pTK6::pRS01 recombinants following pTK6 mobilization from the $\mathrm{Rec}^{-}$donor L. lactis MMS362 is consistent with a transposition or site-specific mechanism for cointegration similar to the transfer of lactose plasmid pSK08 (Anderson \& McKay, 1984b). The inability to mobilize pSA3 indicated that the cloned pTR2030 fragment was necessary for recombination. We have recently identified the presence of an insertion sequence isogenic to ISS1, (Polzin \& Shimizu-Kadota, 1987), residing on the cloned $13.6 \mathrm{~kb}$ fragment of pTR2030 present in pTK6 (Romero \& Klaenhammer, 1990). As is the case with pSK08 conjugal transfer (Anderson \& McKay, 1984b), this insertion sequence probably accounts for the mobilization of pTK6 by pRS01 in MMS362.

Enhanced phage inhibition, relative to pTK6, was a result of a recombination event that was selected through conjugal mobilization. Initially, it could not be ruled out that enhanced resistance was due to the activation of a restriction system effective against phages $\mathrm{c} 2$ and $\mathrm{p} 2$. However, phage from single plaque isolates appearing on NCK178 and NCK179 were c2 phage mutants that did not follow host-dependent $\mathrm{R} / \mathrm{M}$ patterns. Infective centre assays confirmed that phage inhibition was typical of the Hsp responses encoded by pTK6/pTR2030 (Table 3) and not due to an $R / M$ system operating on phages $\mathrm{c} 2$ and $\mathrm{p} 2$. Furthermore, the possibility of a latent resistance mechanism associated with the conjugal elements and expressed following mobilization of pTK6 was excluded: pTRK28-cointegrates generated from $L$. lactis MMS362 and MG1363 did not confer phage 
resistance. Due to the limited number of transconjugants that can be examined in this way, we cannot exclude the possibility that a phage resistance gene on the conjugal element was activated during the specific recombination events leading to the formation of pTRK 78 and pTRK 79; however, we believe this to be unlikely. Nevertheless, it is significant that expression of phage resistance derived from pTK6-cointegrates could be elevated to and beyond the original pTR2030 levels. In addition to effects on $\mathrm{Hsp}, \mathrm{R} / \mathrm{M}$ activities of pTRK 78 and pTRK 79, as detected in L. lactis NCK203 using phage $\phi 48$, were also elevated over that of pTK6. This is consistent with the identification of an $R / M$ system encoded on the $13.6 \mathrm{~kb}$ fragment of pTR2030 cloned on pTK6 which functions independently of $\mathrm{Hsp}$ (Hill et al., $1989 b$ ).

Subcloning the genetic determinants from pTR2030 onto pSA3 resulted in lower levels of phage resistance. The return of 'full' phage resistance imposed by pTK6cointegrates implies that the entire structural gene requirements for Hsp and $\mathbf{R} / \mathbf{M}$ are present on pTK6. Although it is not clear why cointegration would cause elevated phage resistance, it is interesting to note that the physical structures of pTRK 78 and pTRK79 resemble pTR2030, where the resistance determinants are physically linked to conjugative functions. Anderson \& McKay (1984a) described a similar in vivo recombination event where the lac genes from pSK08 were fused to a higher copy number replicon in L. lactis ML3. This resulted in a twofold increase in lac gene dosage. However, the increase in the expression of phospho- $\beta$-Dgalactosidase did not lead to an increased ability of cells harbouring the recombinant plasmid to produce lactic acid in milk. In $E$. coli, subcloning the pif phage resistance determinants from the $\mathrm{F}$ factor onto a $\mathrm{pSC} 101$ vector resulted in increased phage inhibition (Rotman $e t$ $a l ., 1983)$. The authors speculated that this elevation in resistance resulted from increased gene dosage due to the higher copy number of the cloning vector. Relative measurements have indicated that pTK6 was present in approximately $20-30$ copies per cell, whereas pTR2030, pTRK 78 and pTRK 79 were estimated at about 1 copy per cell (unpublished results). This suggests that increased plasmid copy number does not play a role in the elevated phage resistance conferred by pTRK 78 and pTRK 79. Activation of Hsp and R/M did, however, require recombination since the presence of a conjugal element was not sufficient in itself to elevate phage resistance.

A variety of lactococcal plasmids encoding phage resistance that differ in size, types of resistances, and associated characteristics have been described (Klaenhammer, 1987; Sanders, 1988). The degree to which these plasmids interfere with phage development is variable and ranges from partial to complete inhibition of plaquing ability. We have shown that genetic recombination with indigenous conjugal elements may result in enhanced levels of phage resistance affecting both abortive infection and $\mathrm{R} / \mathrm{M}$ activities encoded on pTK6. This suggests that starter strains with improved resistance to bacteriophage attack may be constructed through in vivo genetic engineering of existing determinants. It is significant that elements that promote recombination, such as insertion sequences, are associated with traits such as phage resistance which are advantageous if they can be rapidly disseminated through the population. Furthermore, the R/M activity of pTR2030 may also play a role in promoting recombination events. Price \& Bickle (1986) have conjectured that DNA cleavage caused by $R / M$ systems can provide highly recombinogenic sites, thereby promoting genetic rearrangements. The ability to recombine, coupled with conjugative abilities, may therefore provide an efficient means to disseminate phage resistance in lactococci.

This work was supported in part by the USDA Animal Molecular Biology Program under agreement no. 87-CRCR-1-2547 and by Biotechnology Division of Miles Inc., Elkhart, IN. We wish to thank L. L. McKay and M. J. Gasson for providing strains and W. D. Sing for helpful scientific discussions.

Paper number 12343 of the Journal Series of the North Carolina Agricultural Research Service, Raleigh, NC 27695-7601. The use of trade names in this publication does not imply endorsement by the North Carolina Agricultural Research Service of the products named, nor criticism of similar ones not mentioned.

\section{References}

ANDERSON, D. G. \& MCKAY, L. L. (1983). Simple and rapid method for isolating large plasmid DNA from lactic streptococci. Applied and Environmental Microbiology 46, 549-552.

ANDERSON, D. G. \& MCKAY, L. L. (1984a). In vivo cloning of lac genes in Streptococcus lactis ML3. Applied and Environmental Microbiology 47, 245-249.

Anderson, D. G. \& MCKay, L. L. (1984b). Genetic and physical characterization of recombinant plasmids associated with cell aggregation and high-frequency conjugal transfer in Streptococcus lactis ML3. Journal of Bacteriology 158, 954-962.

DAO, M. L. \& FERRETTI, J. J. (1985). Streptococcus-Escherichia coli shuttle vector pSA3 and its use in cloning of streptococcal genes. Applied and Environmental Microbiology 49, 115-119.

Davies, F. L., Underwood, H. M. \& Gasson, M. J. (1981). The value of plasmid profiles for strain identification in lactic streptococci and the relationship between Streptococcus lactis 712, ML3, and C2. Journal of Applied Bacteriology 51, 325-337.

Fitzgerald, G. F. \& Gasson, M. J. (1988). In vivo gene transfer systems and transposons. Biochimie 70, 489-502.

GASSON, M. J. (1983). Plasmid complements of Streptococcus lactis NCDO 712 and other lactic streptococci after protoplast-induced curing. Journal of Bacteriology 154, 1-9.

Hill, C., Pierce, K. \& Klaenhammer, T. R. (1989a). The conjugative plasmid pTR2030 encodes two bacteriophage defense mechanisms in lactococci, restriction modification $\left(\mathrm{R}^{+} / \mathbf{M}^{+}\right)$and abortive infection $\left(\mathrm{Hsp}^{+}\right)$. Applied and Environmental Microbiology 55, 24162419. 
Hill, C., Romero, D. A., McKenney, D. S., Finer, K. R. \& KLAENHAMMER, T. R. (1989b). Localization, cloning, and expression of genetic determinants for bacteriophage resistance from the conjugative, bacteriophage resistance plasmid pTR2030. Applied and Environmental Microbiology 55, 1684-1689.

JARVis, A. W. \& KLAENHAMmer, T. R. (1986). Bacteriophage resistance conferred on lactic streptococci by the conjugative plasmid pTR2030: effects on small isometric-, large isometric-, and prolate-headed phages. Applied and Environmental Microbiology 51, $1272-1277$.

KEOGH, B. P. (1973). Adsorption, latent period and burst size of phages of some strains of lactic streptococci. Journal of Dairy Research 40, 303-309.

Klaenhammer, T. R. (1987). Plasmid-mediated mechanisms for bacteriophage defense in lactic streptococci. FEMS Microbiology Reviews 46, 313-325.

Klaenhammer, T. R. \& SAnOzKy, R. B. (1985). Conjugal transfer from Streptococcus lactis ME2 of plasmids encoding phage resistance, nisin resistance and lactose-fermenting ability: evidence for a highfrequency conjugative plasmid responsible for abortive infection of virulent bacteriophage. Journal of General Microbiology 131, 15311541.

Klaenhammer, T. R., McKay, L. L. \& Baldwin, K. A. (1978), Improved lysis of group $\mathbf{N}$ streptococci for isolation and rapic characterization of plasmid deoxyribonucleic acid. Applied and Environmental Microbiology 35, 592-600.

VAN DER LELIE, D. (1989). Mechanisms of DNA transfer in lactococci. $\mathrm{PhD}$ thesis, Rijksuniversiteit Groningen.

Luchansky, J. B., Benson, A. K. \& Atherly, A. G. (1989). Construction, transfer and properties of a novel temperaturesensitive integrable plasmid for genomic analysis of Staphylococcus aureus. Molecular Microbiology 3, 65-78.

Macrina, F. L., Kopecko, D. J., Jones, K. R., AYers, D. J. \& MCCOWEN, S. M. (1978). A multiple plasmid-containing Escherichia coli strain: convenient source of size reference plasmid molecules. Plasmid 1, 417-420.

McKay, L. L., Baldwin; K. A. \& Walsh; P. M. (1980). Conjugal transfer of genetic information in group N streptococci. Applied and Environmental Microbiology 40, 84-91.

PRICE, C. \& BICKLE, T. A. (1986). A possible role for DNA restriction in bacterial evolution. Microbiological Sciences 3, 296-299.

Polzin, K. M. \& ShIMIZU-Kadota, M. (1987). Identification of a new insertion element, similar to Gram-negative IS26, on the lactose plasmid of Streptococcus lactis ML3. Journal of Bacteriology 169, 5481-5488.

Rotman, G. S., Cooney, R. \& Malamy, M. H. (1983). Cloning of the pif region of the $\mathrm{F}$ sex factor and identification of a pif protein product. Journal of Bacteriology 155, 254-264.

RoDRIGUEZ, R. L. \& TAIT, R. C. (1983). Recombinant DNA Techniques: an Introduction. Reading, Massachusetts: Addison-Wesley Publishing Company.

Romero, D. A. \& KLAENHAMMER, T. R. (1990). Characterization of Gram-positive insertion sequence IS946, an iso-ISSI element, isolated from the conjugative lactococcal plasmid pTR2030. Journal of Bacteriology 172, 4151-4160.

SANDERS, M. E. (1988). Phage resistance in lactic acid bacteria. Biochimie 70, 411-422.

SANDERs, M. E., Leonard, P. J., Sing, W. D. \& Klaenhammer, T. R. (1986). Conjugal strategy for construction of fast-acid producing, bacteriophage-resistant lactic streptococci for use in dairy fermentations. Applied and Environmental Microbiology 52, 1001-1007.

SilhaVY, T. J., BeRmaN, M. L. \& ENQuist, L. W. (1984). Experiments with Gene Fusions. Cold Spring Harbor, NY: Cold Spring Harbor Laboratory.

Sing, W. D. \& KLAENHAMmer, T. R. (1986). Conjugal transfer of bacteriophage resistance determinants on pTR2030 into Streptococcus cremoris strains. Applied and Environmental Microbiology 51, 1264-1271.

SNOOK, R. J. \& McKaY, L. L. (1981). Conjugal transfer of lactosefermenting ability among Streptococcus cremoris and Streptococcus lactis strains. Applied and Environmental Microbiology 42, 904-911.

SOUTHERN, E. M. (1975). Detection of specific sequences among DNA fragments separated by gel electrophoresis. Journal of Molecular Biology 164, 503-517.

SteEnson, L. R. \& KLAENhammer, T. R. (1985). Streptococcus lactis M12R transconjugants carrying the conjugal plasmid pTR2030 are insensitive to attack by lytic bacteriophages. Applied and Environmental Microbiology 29, 807-813.

TERZAGHI, B. E. \& SANDINE, W. E. (1975). Improved medium for lactic streptococci and their bacteriophages. Applied Microbiology 29, 807-813.

von Wright, A., TAimisto, A.-M. \& Sivelä, S. (1985). Effect of $\mathrm{Ca}^{2+}$ ions on plasmid transformation of Streptococcus lactis protoplasts. Applied and Environmental Microbiology 50, 1100-1102. 